\title{
Ventriculoperitoneal Shunt Peritoneal Catheter Knot Formation
}

\author{
Anwar Ul-Haq, ${ }^{1}$ Faisal Al-Otaibi, ${ }^{1,2}$ Saud Alshanafey, ${ }^{2,3}$ \\ Mohamed Diya Sabbagh, ${ }^{2}$ and Essam Al Shail ${ }^{1,2}$ \\ ${ }^{1}$ Division of Neurosurgery, Neurosciences Department, King Faisal Specialist Hospital and Research Center, \\ P.O. Box 3354, Riyadh 11211, Saudi Arabia \\ ${ }^{2}$ College of Medicine, Alfaisal University, King Faisal Specialist Hospital and Research Center, Riyadh 11533, Saudi Arabia \\ ${ }^{3}$ Division of Pediatric Surgery, Department of Surgery, King Faisal Specialist Hospital and Research Center, \\ Riyadh 11211, Saudi Arabia \\ Correspondence should be addressed to Faisal Al-Otaibi; faisalruwais@gmail.com
}

Received 30 July 2013; Accepted 15 August 2013

Academic Editors: A. K. Demetriades and V. Wang

Copyright (C) 2013 Anwar Ul-Haq et al. This is an open access article distributed under the Creative Commons Attribution License, which permits unrestricted use, distribution, and reproduction in any medium, provided the original work is properly cited.

\begin{abstract}
The ventriculoperitoneal (VP) shunt is a common procedure in pediatric neurosurgery that carries a risk of complications at cranial and abdominal sites. We report on the case of a child with shunt infection and malfunction. The peritoneal catheter was tethered within the abdominal cavity, precluding its removal. Subsequently, laparoscopic exploration identified a knot at the distal end of the peritoneal catheter around the omentum. A new VP shunt was inserted after the infection was healed. This type of complication occurs rarely, so there are a limited number of case reports in the literature. This report is complemented by a literature review.
\end{abstract}

\section{Introduction}

Ventriculoperitoneal (VP) shunt insertion is one of the most common procedures performed in neurosurgical practice. The abdominal complications of VP shunt insertion include cerebrospinal fluid (CSF) ascites, loculated cysts, hydrocele, infection, shunt extrusion, shunt migration, CSF leaks, viscous perforations, and protrusion of the catheter from the anus $[1,2]$. Spontaneous knotting of the peritoneal catheter is a rare complication of the VP shunt [3]. Here, we report a case of knotting of the peritoneal catheter discovered during the removal of a malfunctioning VP shunt. The knotting of the catheter hindered its removal; the catheter was later removed laparoscopically.

\section{Case Report}

This particular case refers to an eight-year-old boy who was born with a congenital hydrocephalus and large parietooccipital skull defect. He underwent VP shunt insertion after birth. He then underwent cranioplasty with titanium mesh and acrylic bone cement on January 20, 2009. One month later, he was presented to the emergency room with a severe headache and blurred vision. His ventricular catheter had migrated out of the ventricle, and the shunt was not functioning. An emergency external ventricular drain was inserted, which was replaced later with a VP shunt. A peritoneal catheter was inserted laparoscopically. Two years later, the boy returned with a headache, vomiting, fever, and seizures. The results of a CSF analysis indicated infection, and a Computed Tomography (CT) scan of his brain showed hydrocephalus, suggesting a shunt malfunction (Figure 1). A VP shunt X-ray series showed that the peritoneal catheter was coiled in the abdomen (Figure 2). He underwent removal of the VP shunt and insertion of an external ventricular drain. The ventricular catheter was removed easily prior to the insertion of the external drain. During removal, it was noted that the peritoneal catheter was difficult to remove and felt tethered at the abdominal entrance site. The upper part of the peritoneal catheter was cut and removed, and the remaining part was left in place to be dealt with later. Once the CSF infection cleared, the patient again underwent VP shunt insertion with the laparoscopic-assisted approach. During the procedure, it was noticed that there was a knot at the distal end of the peritoneal catheter, and the catheter was stuck at the inner surface of the abdominal wall near the point of its 


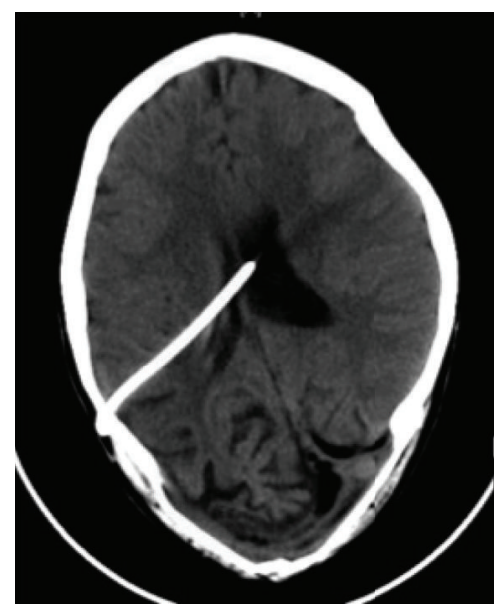

(a)

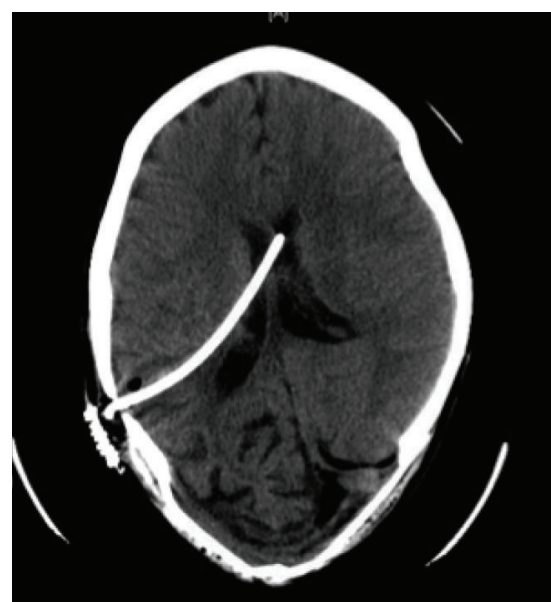

(b)

Figure 1: Computed Tomography of the brain demonstrating dilated ventricular system as a sign of ventriculoperitoneal shunt malfunction (a) and the reduction in ventricular size after VP shunt revision (b).

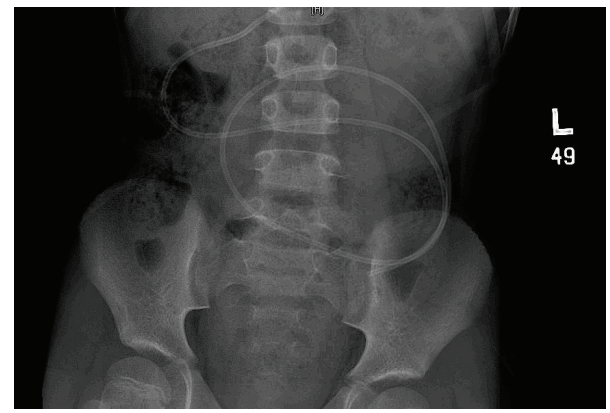

Figure 2: Abdominal X-ray showing the peritoneal catheter with early large knot formation.

entrance (Figure 3). The omentum adhered to the abdominal wall at the point of entrance of the peritoneal catheter. The peritoneal catheter was removed through a separate port, and a new VP shunt was implanted. Subsequently, the patient did well and was discharged home in a healthy state.

\section{Discussion}

VP shunt implantation is the most common surgical procedure used to treat hydrocephalus. This procedure has a variety of complications, including shunt obstruction, infection, fracture, disconnection, migration, subcutaneous extrusion, or protrusion of the catheter. These problems may relate to the ventricular catheter, shunt reservoir, or peritoneal catheter. Abdominal complications are reported in 5-47\% of VP shunt cases [1]. Such complications include CSF ascites, hydrocele, loculated peritoneal cysts, bowel perforations, peritoneal catheter obstruction by omental adhesions, subcutaneous extrusion of the peritoneal catheter, CSF fistula, incisional hernia, and protrusion of the peritoneal catheter from the anus [1,4-8]. Knot formation on the peritoneal catheter is an extremely rare complication of VP shunt insertion $[9,10]$.

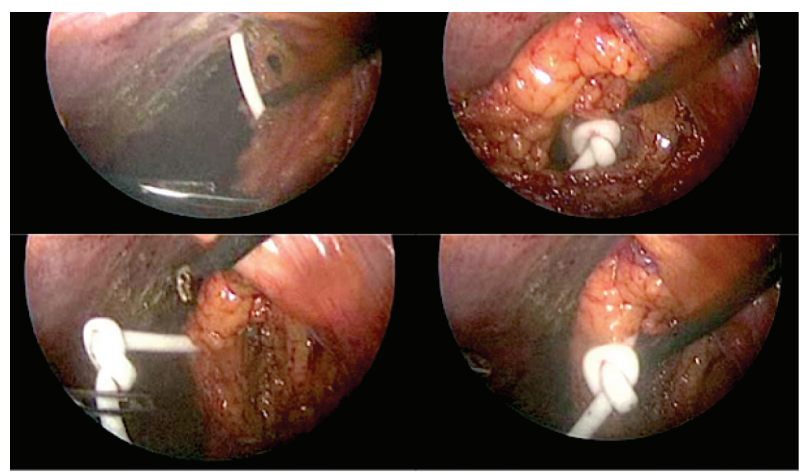

FIGURE 3: Laparoscopic view depicting the knot formation at the distal peritoneal catheter embedded within omentum.

To date, there are a limited number of case reports available. Table 1 summarizes the reported cases of peritoneal catheter knot formation.

The formation of a knot in a peritoneal catheter commonly results in VP shunt malfunction [3, 9, 11-13]. Knotting of the catheter around the bowel can lead to bowel obstruction and gangrene $[4,14]$. Occasionally, the knot is an incidental finding [10]. The issue can be diagnosed by a VP shunt X-ray series and CT scan. Treatment consists of laparoscopic exploration of the peritoneal cavity or minilaparotomy. The peritoneal catheter can be unknotted or removed and replaced with a new catheter; alternatively, the whole shunt system can be replaced [15].

Knot formation usually occurs at the terminal end of the peritoneal catheter. The exact mechanism of knot formation is not clearly known. The various factors proposed by different authors include catheter characteristics, capacity and configuration of abdominal cavity, and direction of catheter movement [11]. A catheter's greater length, lesser diameter, and highly elastic material predispose it to knotting. 
TABLE 1: Summary of reported cases of peritoneal catheter knot formation.

\begin{tabular}{|c|c|c|c|c|c|}
\hline Author/year & Age/sex & Basic pathology & $\begin{array}{l}\text { Time interval between } \\
\text { shunt and presentation }\end{array}$ & Presentation & Management \\
\hline $\begin{array}{l}\text { Starreveld et al. } \\
(1998)[4]\end{array}$ & 7 days/F & Hydrocephalus & NA & Bowel gangrene & $\begin{array}{l}\text { Bowel resection and } \\
\text { ventriculoatrial shunt }\end{array}$ \\
\hline $\begin{array}{l}\text { Toshifumi and } \\
\text { Tatsuro (2001) [14] }\end{array}$ & $63 \mathrm{Y} / \mathrm{M}$ & Head injury and hydrocephalus & 20 years & $\begin{array}{l}\text { Bowel obstruction } \\
\text { without gangrene }\end{array}$ & $\begin{array}{l}\text { Laparotomy and } \\
\text { unknotting of the catheter }\end{array}$ \\
\hline $\begin{array}{l}\text { Chopra et al. } \\
(2004)[11]\end{array}$ & $25 \mathrm{Y} / \mathrm{F}$ & $\begin{array}{l}\text { Bithalamic glioma and } \\
\text { hydrocephalus }\end{array}$ & 2 months & Shunt malfunction & $\begin{array}{l}\text { Excision of knotted } \\
\text { catheter segment }\end{array}$ \\
\hline $\begin{array}{l}\text { Woerdeman and } \\
\text { Hanlo (2006) [12] }\end{array}$ & 10 days/M & $\begin{array}{l}\text { Chiari malformation and } \\
\text { myelomeningocele }\end{array}$ & 3 days & Shunt malfunction & Unknotting of the catheter \\
\hline $\begin{array}{l}\text { Eftekhar and Hunn } \\
\text { (2008) [13] }\end{array}$ & $3.5 \mathrm{Y} / \mathrm{M}$ & Hydrocephalus & 39 months & Shunt malfunction & Unknotting of the catheter \\
\hline $\begin{array}{l}\text { Mohammed et al. } \\
\text { (2011) [9] }\end{array}$ & $14 \mathrm{Y} / \mathrm{M}$ & Congenital hydrocephalus & NA & Shunt malfunction & Shunt revision \\
\hline $\begin{array}{l}\text { Borcek et al. (2012) } \\
\text { [3] }\end{array}$ & $3 \mathrm{Y} / \mathrm{M}$ & Head injury & 34 months & Shunt malfunction & Shunt revision \\
\hline $\begin{array}{l}\text { Mohindra and } \\
\text { Sharma (2012) [10] }\end{array}$ & $10 \mathrm{Y} / \mathrm{M}$ & $\begin{array}{l}\text { Congenital hydrocephalus and } \\
\text { Crouzon's syndrome }\end{array}$ & 7 Years & Incidental & Nil \\
\hline Present case & $8 \mathrm{Y} / \mathrm{M}$ & $\begin{array}{l}\text { Congenital calvarial defect and } \\
\text { hydrocephalus }\end{array}$ & 2 months & $\begin{array}{l}\text { Shunt infection } \\
\text { and malfunction }\end{array}$ & Shunt revision \\
\hline
\end{tabular}

NA: no available data.

Increased abdominal volume, crowding of abdominal contents, intra-abdominal adhesion, and vigorous peristalsis can also trigger knot formation [10]. Raymer and Smith reported on the mechanism of knot formation [16]. The researchers placed a string perpendicular to the pull of gravity within a rotating cubic box, causing the string to form a knot. The authors found that the length of string and the increase in string motion raise the probability of knot formation. In our case, knot formation occurred during the removal of the peritoneal catheter due to the adhesions of the omentum to the point of entry of the peritoneal catheter.

\section{Conclusion}

Knotting of the peritoneal catheter is a rare complication of the VP shunt. The exact mechanism of knot formation remains poorly understood. Asymptomatic knots on the peritoneal catheter can be observed with serial VP shunt $\mathrm{X}$-ray series and a CT scan, and symptomatic patients require laparoscopic exploration and the unknotting or total replacement of the peritoneal catheter.

\section{Conflict of Interests}

The authors have no conflict of interests.

\section{References}

[1] J. Chung, J. Yu, H. K. Joo, J. N. Se, and M. Kim, "Intraabdominal complications secondary to ventriculoperitoneal shunts: CT findings and review of the literature," American Journal of Roentgenology, vol. 193, no. 5, pp. 1311-1317, 2009.
[2] F. R. Murtagh, R. M. Quencer, and C. A. Poole, "Extracranial complications of cerebrospinal fluid shunt function in childhood hydrocephalus," American Journal of Roentgenology, vol. 135, no. 4, pp. 763-766, 1980.

[3] A. O. Borcek, S. Civi, M. Golen, H. Emmez, and M. K. Baykaner, "An unusual ventriculoperitoneal shunt complication: spontaneous knot formation," Turkish Neurosurgery, vol. 22, no. 2, pp. 261-264, 2012.

[4] Y. Starreveld, D. Poenaru, and P. Ellis, "Ventriculoperitoneal shunt knot: a rare cause of bowel obstruction and ischemia," Canadian Journal of Surgery, vol. 41, no. 3, pp. 239-240, 1998.

[5] S. W. Sturdee, J. Timothy, and A. Tyagi, "Total extrusion of a cranial peritoneal shunt per rectum," Journal of Clinical Neuroscience, vol. 9, no. 2, pp. 199-200, 2002.

[6] M. E. Fewel and H. J. L. Garton, "Migration of distal ventriculoperitoneal shunt catheter into the heart: case report and review of the literature," Journal of Neurosurgery, vol. 100, supplement 2, pp. 206-211, 2004.

[7] A. Ammar, A. W. M. Ibrahim, M. Nasser, and M. Rashid, "CSF hydrocele-unusual complication of V-P shunt," Neurosurgical Review, vol. 14, no. 2, pp. 141-143, 1991.

[8] D. Karaosmanoglu, Y. Metin, D. Akata, and M. Haliloğlu, “An unusual cause of hydrocele: malpositioned ventriculoperitoneal shunt in the scrotum," Journal of Ultrasound in Medicine, vol. 27, no. 1, pp. 159-160, 2008.

[9] W. Mohammed, U. Wiig, and J. Caird, "Spontaneous knot; a rare cause of ventriculoperitoneal shunt blockage," British Journal of Neurosurgery, vol. 25, no. 1, pp. 113-114, 2011.

[10] S. Mohindra and M. Sharma, "Spontaneous knotting of peritoneal catheter: a report of an asymptomatic patient," Journal of Pediatric Neurosciences, vol. 7, no. 2, pp. 151-153, 2012.

[11] I. Chopra, K. Gnanalingham, D. Pal, and D. Peterson, "A knot in the catheter-an unusual cause of ventriculo-peritoneal shunt blockage," Acta Neurochirurgica, vol. 146, no. 9, pp. 1055-1057, 2004 . 
[12] P. A. Woerdeman and P. W. Hanlo, "Ventriculoperitoneal shunt occlusion due to spontaneous intraabdominal knot formation in the catheter: case report," Journal of Neurosurgery, vol. 105, supplement 3, pp. 231-232, 2006.

[13] B. Eftekhar and A. Hunn, "Ventriculoperitoneal shunt blockage due to spontaneous knot formation in the peritoneal catheter: case report," Journal of Neurosurgery, vol. 1, no. 2, pp. 142-143, 2008.

[14] S. N. K. Toshifumi and I. Tatsuro, "Intesitinal obstruction caused by ventriculoperitoneal shunt knot. A case report," Journal of the Iwate Medical Association, vol. 53, no. 1, pp. 4346, 2001.

[15] S. M. Kavic, R. D. Segan, M. D. Taylor, and J. S. Roth, "Laparoscopic management of ventriculoperitoneal and lumboperitoneal shunt complications," Journal of the Society of Laparoendoscopic Surgeons, vol. 11, no. 1, pp. 14-19, 2007.

[16] D. M. Raymer and D. E. Smith, "Spontaneous Knotting of an agitated string," Proceedings of the National Academy of Sciences of the United States of America, vol. 104, pp. 1643-1647, 2007. 


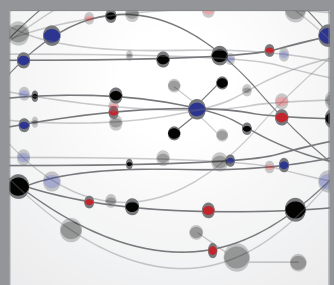

The Scientific World Journal
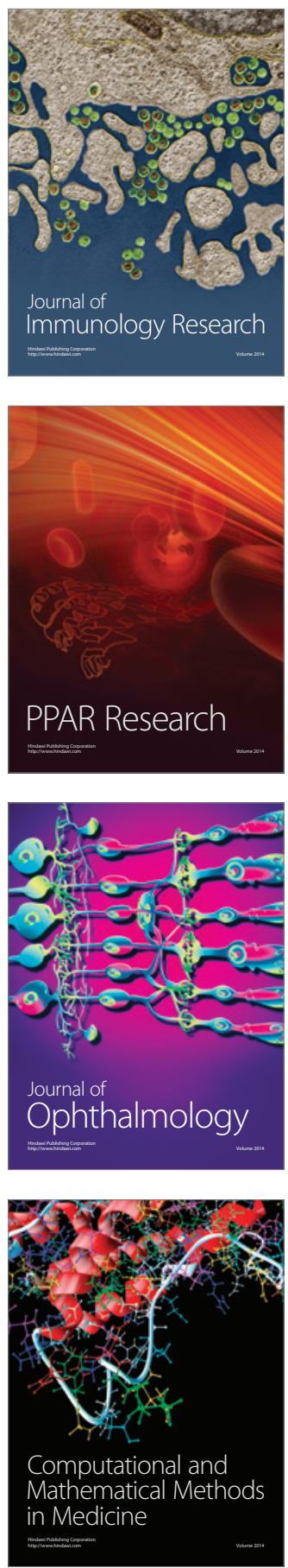

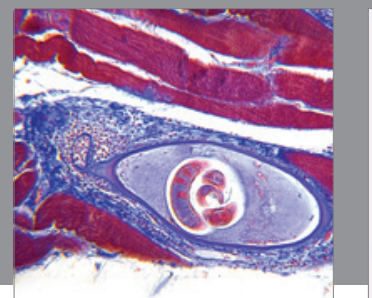

Gastroenterology

Research and Practice
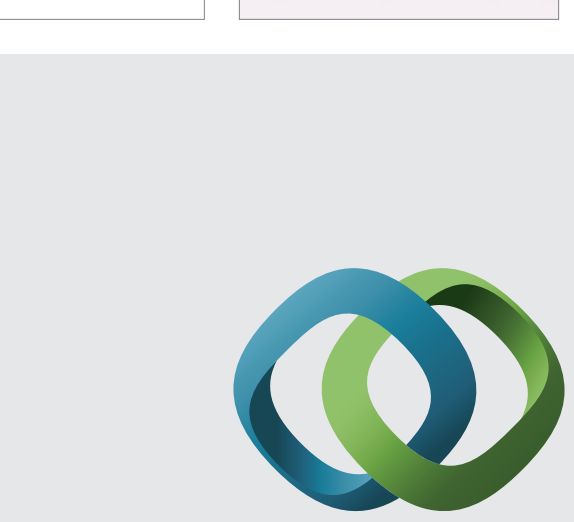

\section{Hindawi}

Submit your manuscripts at

http://www.hindawi.com
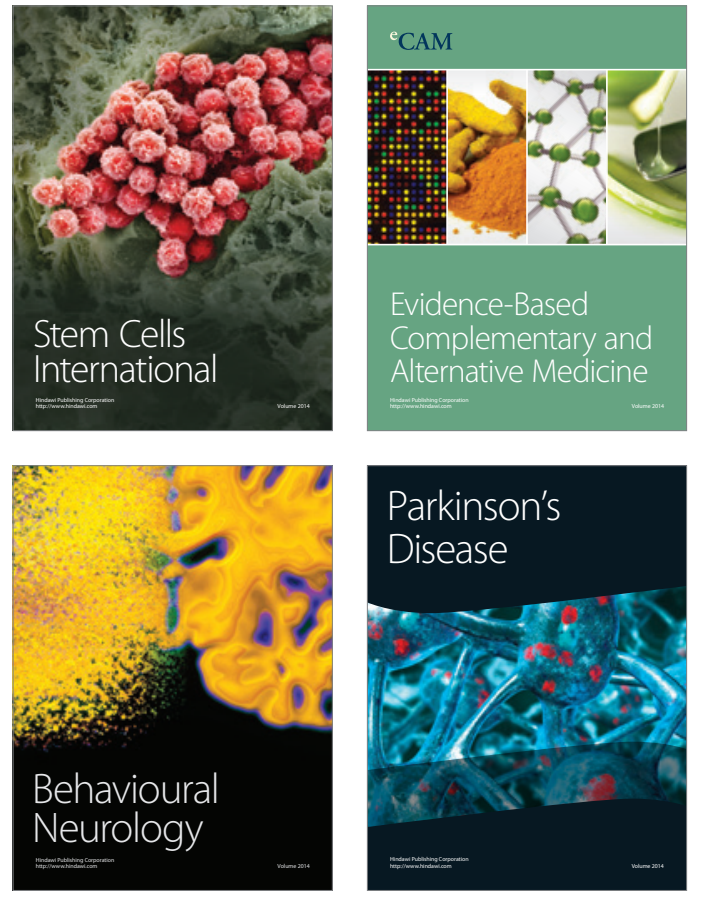
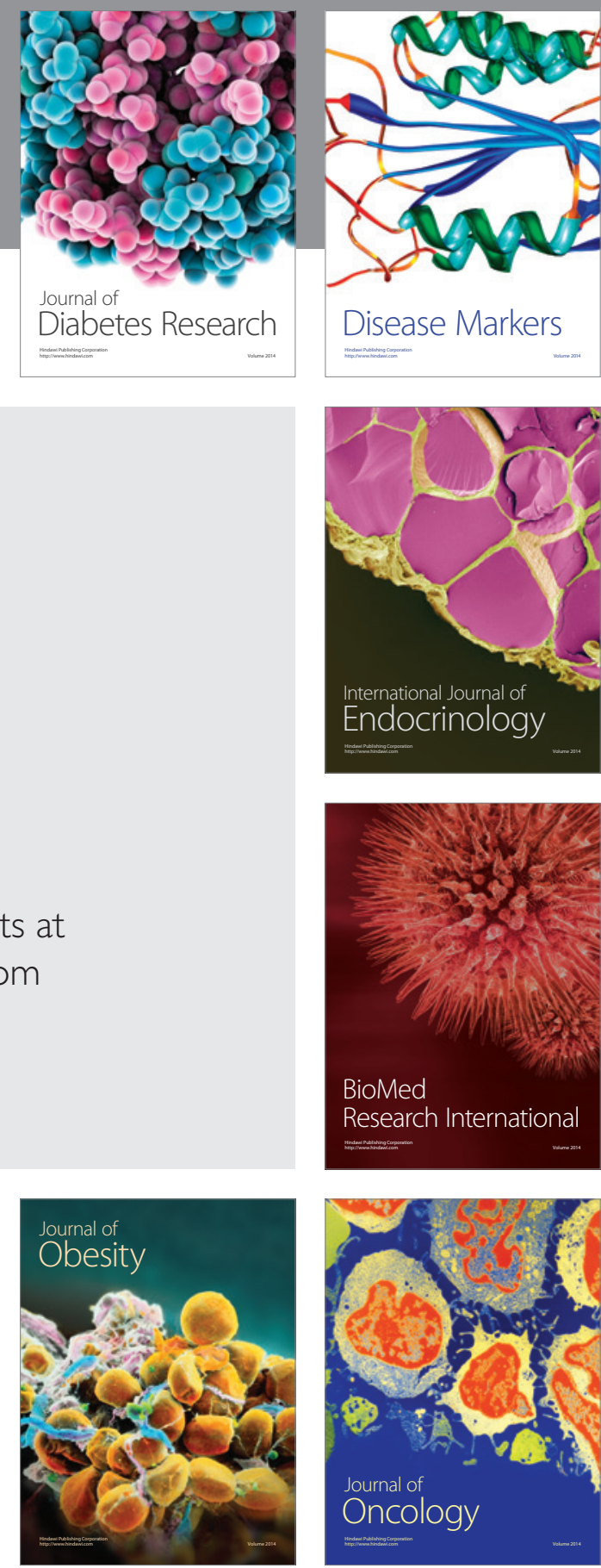

Disease Markers
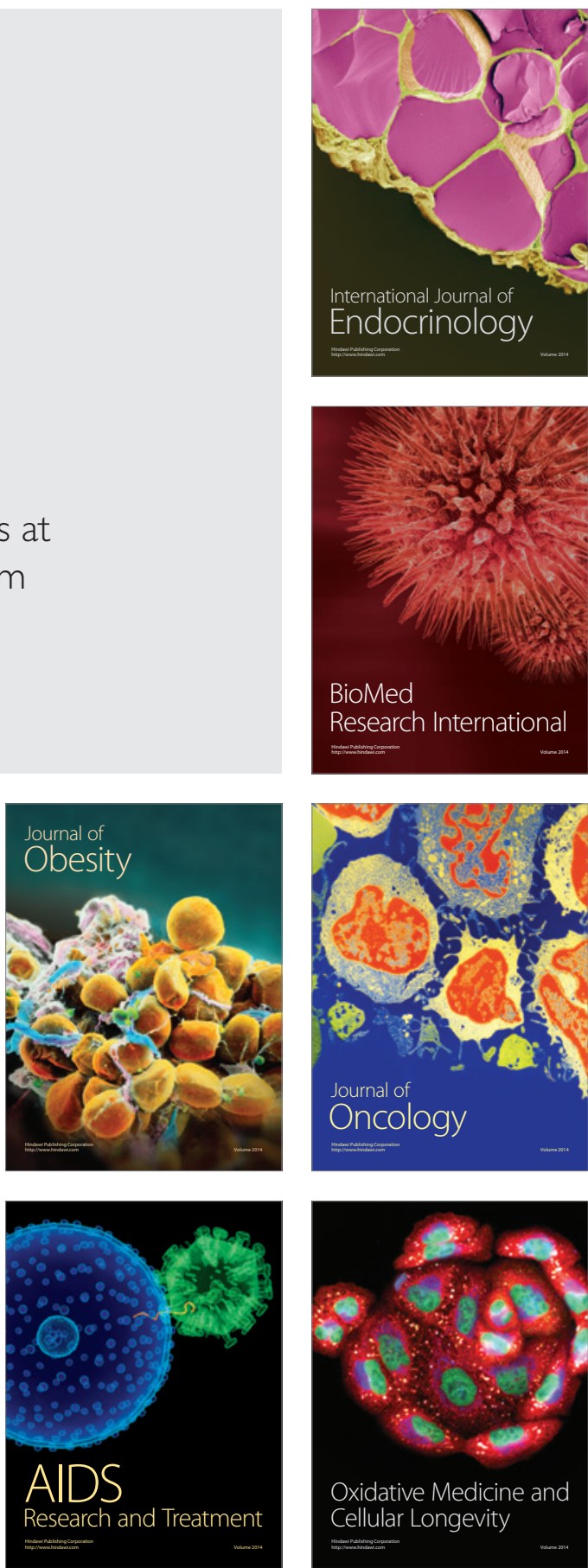